\title{
Combination of real options and game-theoretic approach in investment analysis
}

\author{
Abdollah Arasteh ${ }^{1}$ \\ Received: 6 April 2015/Accepted: 3 February 2016/Published online: 20 February 2016 \\ (c) The Author(s) 2016. This article is published with open access at Springerlink.com
}

\begin{abstract}
Investments in technology create a large amount of capital investments by major companies. Assessing such investment projects is identified as critical to the efficient assignment of resources. Viewing investment projects as real options, this paper expands a method for assessing technology investment decisions in the linkage existence of uncertainty and competition. It combines the game-theoretic models of strategic market interactions with a real options approach. Several key characteristics underlie the model. First, our study shows how investment strategies rely on competitive interactions. Under the force of competition, firms hurry to exercise their options early. The resulting "hurry equilibrium" destroys the option value of waiting and involves violent investment behavior. Second, we get best investment policies and critical investment entrances. This suggests that integrating will be unavoidable in some information product markets. The model creates some new intuitions into the forces that shape market behavior as noticed in the information technology industry. It can be used to specify best investment policies for technology innovations and adoptions, multistage $\mathrm{R} \& \mathrm{D}$, and investment projects in information technology.
\end{abstract}

Keywords Investment analysis - Real options · Game theory $\cdot$ Information technology

Abdollah Arasteh

arasteh@nit.ac.ir

1 Industrial Engineering Department, Babol Noshirvani

University of Technology, Shariati Av.,

P.O. Box: 484, Babol, Mazandaran, Iran

\section{Introduction}

\section{Investments in information technologies}

Historically, creating infrastructure needed huge investment. In the change from an industrial economy to an information-based one, companies today invest huge quantities of resources in new information technologies (IT) and connected infrastructures. In the information era, the necessary assets for business success are no longer factories, but knowledge assets and the allowing technological infrastructures (Albuquerque and Miao 2014; Berghman et al. 2012).

From a single firm's viewpoint, an early investment in IT infrastructure may result in getting a "power" that would let the firm take better advantage of future growth opportunities. This is mainly important for information thorough firms, where a firm's information infrastructure gets progressively essential to its ability to apply new business strategies. An ordinary benefit of IT investments is the ability to engage in the product markets at lower incremental cost or better customer attraction. Particularly, a firm that has already made such IT-increasing infrastructure investments might launch new business strategies that create or support competitive benefits at lower cost compared with other firms that have not made similar investments (Alexandrov and Deb 2012; Amram and Kulatilaka 1999; Gao et al. 2013).

\section{The difficulty in evaluating IT investments}

Proof has shown that businesses have problems in assessing investment decisions in IT field. Part of these problems were presented as the "productivity paradox" (Brynjolfsson 1993; Dewan and Kraemer 1998). So far, the 
assessment problem is basic to the continuous innovation and application of IT in business. To assess IT investment is hard because available assessment methods have not developed at the same speed as the needs of present practice. IT investments provide firms with growth chances to change to new business events, or get business growth through the exercise of IT-based strategies. Besides, strategic IT investments often affect the behavior of participants. From these causes, assessment of an investment project relied on potential competitive effect is different from assessment relied on cash flows (Dimitrios et al. 2013; Merali et al. 2012).

Assessing IT investment projects creates a few problems that investing in the traditional assets does not introduce. The emphasis shifts from calculating the cash flows to assessing strategic effects that IT investments give: the value of real-time information, managerial flexibility, the ability to answer to unpredicted moves by opponents, and an improved information infrastructure that may have a long-term suggestion for the competitiveness of the firm. To express the value of the decision flexibility set in technology investments, we need searching for new methods to assess technology investment projects (Berghout and Tan 2013; Khallaf 2012).

\section{Technology investments as real options}

Investment projects in IT can be analyzed as sets of real options: a firm with an opportunity to invest in a technology is taking an option similar to a financial call option-it has the right, but not the need, to get the asset at some future time. So, making an investment is similar to exercising a call option with an exercise price proper for the investment expenses, and the underlying asset is the new technology. From a real options viewpoint, also, IT investment is about real options. Real options can be either "simple" options or combined options. A "simple" option is almost like a call option where the exercise of the option guides to the gain of the underlying asset. In combined options, the exercise of one option guides to the gain of another option. Most of the sequential investments can be analyzed as combined options in the feeling the investment in one period gives the firm the option to continue to the next period. Today's investments may have characteristics that will allow a firm to exercise a particular strategy in the future (Fernandes et al. 2013; McIntyre and Chintakananda 2013; Rohlfs and Madlener 2013).

As discussed earlier, investing in growth options rather than cash flows is one of the key characteristics of technology investment. Many multiperiod strategic investments have a negative NPV when analyzed without relation to others, even though they may have significant growth option value. The NPV and options valuation methods may give different results.

The likeness between financial and real options gives the potential the options-pricing theory could be expanded to assessing investment decisions on technological assets? Nonetheless studies of real-options based method for IT investments are still rare; the literature appears in this area, specifying the increasing attention paid to real options.

Its benefit over other capital budgeting methods like DCF analysis has been broadly identified in considering the strategic investment decision under uncertainties (Amram and Kulatilaka 1999; Luehrman 1998a, b). Smith and McCardle (1998, 1999) moreover show that option pricing can be combined with a standard decision analysis framework to get the best of the both worlds. Some previous IS researches have identified many IT investment projects hold some option-like characteristics (Clemons; Dos Santos 1991; Kumar 1996). Benaroch and Kauffman (1999) and Taudes et al. (2000) have applied the real options theory to real-world business cases and assessed this approach's benefits as a tool for IT investment planning. Kim and Sanders (2002) expand a framework of strategic actions relied on real option theory. Some researchers use real options combined with game theory to analyze strategic technology adoption. For example Huisman and Kort (2004) find out a dynamic duopoly in which firms take part in the adoption of new technologies. Smit and Trigeorgis (2006) illustrate the use of real options valuation and game theory concepts to consider original investment opportunities including important strategic decisions under uncertainty. It uses innovation cases, unions and gains to discuss strategic and competitive features, applicable in industries like consumer electronics and telecom. Wu and Ong (2008) in an interesting paper used real options analysis in association with classical financial theory, specifically, the Mean-Variance (MV) model to give new viewpoints on project selection. Pendharkar (2010) used the market asset disclaimer supposition and expand a binomial lattice based real options model to involve cash flow interrelations between multiperiod IT investments. Wu et al. (2012) use a combination of real options and game theory to consider the investment strategies of a case company in the TFT-LCD industry. Martzoukos and Zacharias (2013) demonstrate to decision makers how to optimally make costly strategic pre-investment $R \& D$ decisions in the existence of full results in an option pricing structure with logical tractability. van Zee and Spinler (2014) illustrates a real options method for valuing public-sector research and development projects, using a down-and-out barrier option. 


\section{Competition in technology investment}

Viewing an IT investment project as a real option puts greater importance on the possibilities and benefits of postponing investment to wait for more information to resolve uncertainty. Although, investment opportunities for new technologies are scarcely dedicated, as thorough competition and low barriers of entrance are distinguishing features of the IT industry. Competition over limited investment opportunities may decrease a firm's option value, or still force the option to run out too early. Therefore, the timing of the investment decision could have notable results on the recognized value of the project (Bos et al. 2013; Chaton and Guillerminet 2013).

When to exercise a real option is a strategic decision. If the option is non-dedicated, the firm and its competitors hold an option on the identical asset, and whoever exercises first may get the fundamental asset. The problem is that provided uncertainty stays on the market or technology, no one can be certain that they want the asset. The problem is naturally that no firm knows what condition the game will be in at future times. Also, in a market of incomplete competition, one firm's decision could change the market price and structure. This may have extra strategic impacts on competitor's behavior.

Another typical supposition made in the most of the literature is that information is symmetric that means each firm has complete information about the other's profit structures and that they split similar opinions about future market demands. That is, market demand may continue stochastically, but this is supposed to be public information. So firms are critically supposed to be consistently informed, and no personal and incomplete information is included. Although, in the real world, competition often happens in a situation of information asymmetry. That is, companies have incomplete and asymmetrically assigned information on boundaries like development costs or market demands (Lestage et al. 2013; Wang et al. 2012; Wrzaczek and Kort 2012).

In this paper analyzing the common results of both uncertainty and competition, this paper expands a method to assess investment decisions in an oligopolistic structure. It combines the real options structure with strategic limits of game theory, and prepares a greater comprehension of the results of uncertainty and competition on the strategic exercise of real options inserted in technology investments.

\section{Major contributions of the paper}

The majority of real options researches, has concentrated on business sector situations without strategic collaborations. The extensive greater part of the models of capital speculations, which utilize a real options methodology, has regularly been founded on two particular suspicions: (a) the firm has an imposing business model control over a venture opportunity; and (b) the item market is consummately aggressive. Accordingly, speculation not influence either costs or business sector structure. Strategic issues have rather fallen in the space of modern association. The strategic methodology in modern association writing endogenizes business sector structure; be that as it may, it regularly disregards instability and along these lines the option value of adaptability.

Considering the joint impacts of both uncertainty and competition, this paper adds to a system to assess speculation choices in an oligopolistic business sector structure. The technique separates itself by demonstrating options exercise under endogenous, multi-period competition in the setting of innovation speculation. Through building up a balance model of a dynamic venture diversion, the paper makes a few particular commitments:

First, our study amplifies the ordinary single-specialists improvement models to a game-theoretic setting that consolidates numerous, contending firms. Under the weight of aggressive acquisition, firms race to practice their alternatives early. This significantly dissolves the option value of holding up and changes the key conduct of capital speculation. The model's consequences help clarify some forceful venture examples saw in the IT industry. The second contribution is identified with the assessment of real options when the suspicions for monetary option valuing hypothesis no more hold. On the off chance that the future settlements and the dangers of an innovation speculation undertaking can be reproduced by exchanged resources, the valuation of real option is the clear utilization of the money related option valuation models. Be that as it may, difficulty arises in most of the real asset investment projects. We propose a technique taking into account diversion hypothesis and dynamic programming to assess speculation projects when suspicions for financial option pricing hypothesis don't hold. Third, we derive optimal venture approaches and basic speculation limits. The model is further stretched out to the multi-period setting. Dynamic programming is utilized to handle between worldly speculation choices. Forth, our work amplifies the fulldata models in the researches to a more practical uneven data connection.

In summarize, the differences between our present model and the real options models in the literature are: 
- Our model includes strategic interactions and competitive risks;

- These strategic elements influence the equilibrium and investment behavior (such as early exercise and violent investment);

- The option value is lower but more realistic than that examined in the real options literature;

- Our model analyzes asymmetric information.

- Our model identifies the option value of waiting to better resolve uncertainty;

- This option value is not only conceptualized but also quantified in the present model;

- We continue the consideration to multi-period setting with the linkage existence of continuous uncertainty and competition through a method called "dynamic programming with externalities";

- We endogenize the timing and the leader-follower sequence of investment.

\section{The impact of competition on investment: a simple model}

In this section, we use a simple model to show the basic ideas of investment under competition. First, let us explain the particular problem. Assume firm $X$ encounters a decision whether to take on an investment project. For a cost of $C$, firm $X$ can commercialize a new technology and begin a product into the market. The market demand is uncertain. To remain it simple, suppose the market demand could be "low" with probability $p$ or "high" with probability $1-p$. The net edge of purchasing one unit of the product is $s$ dollars. Suppose the firm uses a discount rate of $i$. The project life is $n$ years; technology grows outdated next. For clarity, suppose that if the firm waits a year it will be able to analyze uncertainty. If we follow the traditional DCF analysis, we may calculate NPV as follows:

$$
\begin{aligned}
\mathrm{NPV}(\text { invest now })= & -C+p\left[\sum_{t=0}^{n-1} \frac{1}{(1+i)^{t}} D_{L} s\right] \\
& +(1-p)\left[\sum_{t=0}^{n-1} \frac{1}{(1+i)^{t}} D_{H} s\right]
\end{aligned}
$$

The NPV rule would tell us to drop the project if $\mathrm{NPV}<0$, invest if $\mathrm{NPV}>0$, and be unconcerned if $\mathrm{NPV}=0$.

\section{The option to defer investment}

A key defect of the above static analysis is that it ignores the option to "wait and see". The investment opportunity is

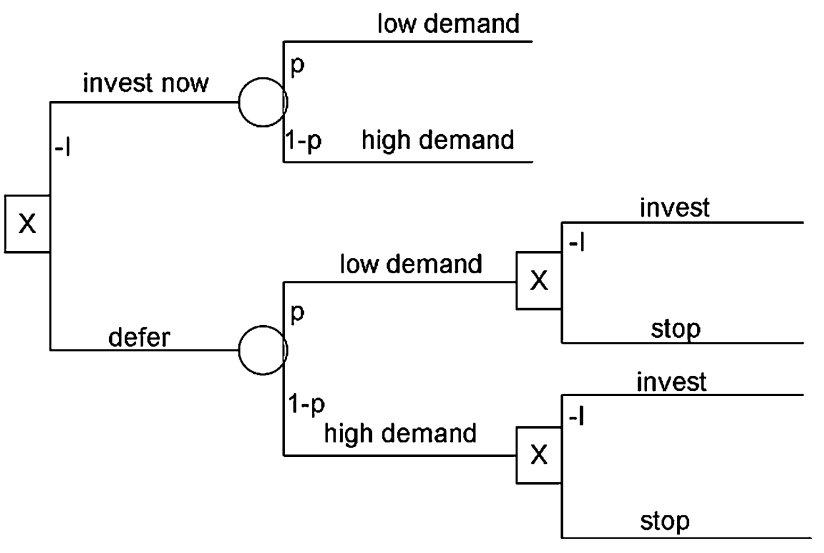

Fig. 1 The option to defer investment

not a "now-or-never" selection. The firm could wait to get more information about the market uncertainty. Figure 1 shows this "wait and see" option.

The NPV of this "wait and see" option is

$$
\begin{aligned}
\mathrm{NPV} \text { (wait) }= & \frac{p}{1+i}\left\{\max \left[0,-C+\left(\sum_{t=0}^{n-2} \frac{1}{(1+i)^{t}}\right) D_{L} s\right]\right\} \\
& +\frac{1-p}{1+i}\left\{\max \left[0,-C+\left(\sum_{t=0}^{n-2} \frac{1}{(1+i)^{t}}\right) D_{H} s\right]\right\}
\end{aligned}
$$

The difference between these values in (1) and (2) show the value of the "wait and see" option. Therefore,

$O=\left|\mathrm{NPV}_{\text {wait }}-\mathrm{NPV}_{\text {invest now }}\right|$

The options-based analysis expresses the value of waiting, which is a development over the static NPV method. Although, it is right only if the investment opportunity stays obtainable for the firm during the period of waiting (Meyer and Rees 2012). This is to suppose the investment opportunity is dedicated, i.e., only one firm has the ability to go into the market. So, the above analysis may have overestimated the option value of waiting as it ignores the risk of competitive entrance.

\section{Investment opportunity under competition}

To cure the above consideration, our model would have to include the risk of competitive entrance. Assume market research leads us to think that with probability $q$ one of the participating firms will enter the market during the first period. Figure 2 shows a changed model that involves competition.

From the real options' viewpoint, the option may be pressure to expire rashly because of competitive entrance. This alters the NPV of the "wait and see" alternative to: 
Fig. 2 Investment option under competition low demand

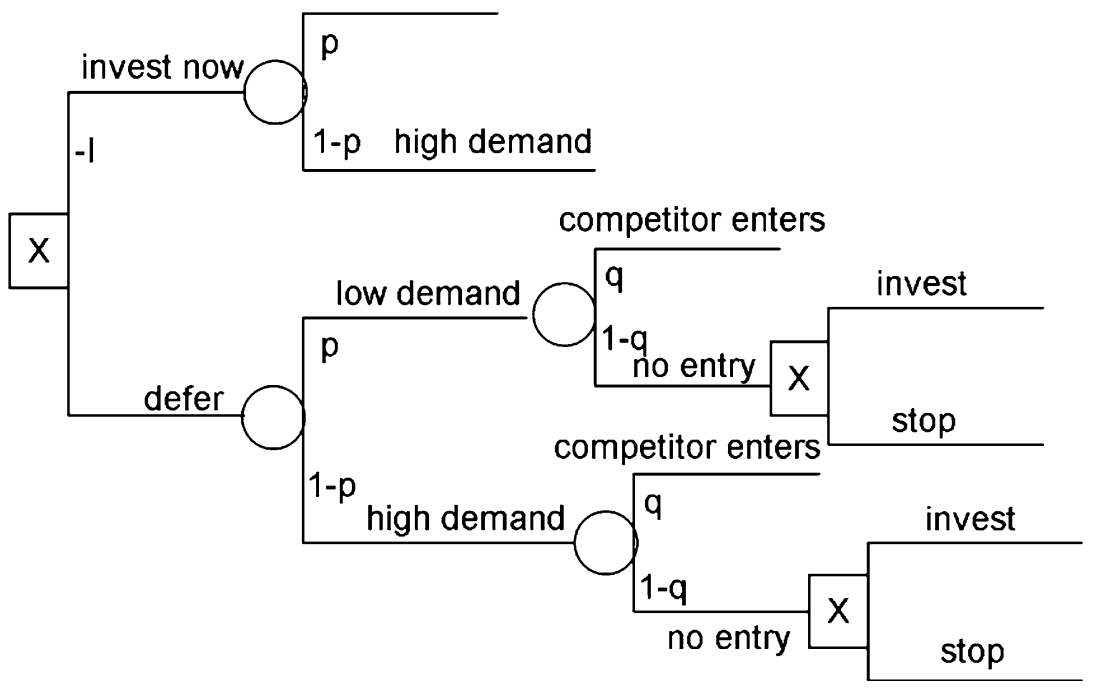

NPV (wait, $w /$ competition)

$$
\begin{aligned}
= & \frac{p(1-q)}{1+i} \max \left[0,-C+\left(\sum_{t=0}^{n-2} \frac{1}{(1+i)^{t}}\right) D_{L} s\right] \\
& +\frac{(1-p)(1-q)}{1+i} \max \left[0,-C+\left(\sum_{t=0}^{n-2} \frac{1}{(1+i)^{t}}\right) D_{H} s\right] \\
= & (1-q) \mathrm{NPV} \text { (wait, no competition) }
\end{aligned}
$$

Similar to the description in (3), the option value is the distinction between the two NPV values in (1) and (4), i.e.,

$O_{\text {with competition }}=\mathrm{NPV}_{\text {wait. with competition }}-\mathrm{NPV}_{\text {invest now }}$

It is easy to prove that (4) is smaller than (2), as long as $q>0$. That is to say, the option value of waiting with competition is smaller than that without competition, as long as there is a positive probability of competitive entrance. By analyzing the result of competition on the real options value, we could say that competition abrade the option value of waiting.

\section{An example}

To put the above examination in the connection of a particular illustration, we accept the numbers are: $C=\$ 7500$, $p=0.75, i=15 \%, s=\$ 12, D_{L}=D, D_{H}=2 D$. Suppose $D$ is known and $D=97.5$. Subsequent to connecting to these numbers, Eqs. (1) and (2) yield NPV (invest now) $=408$ and NPV (wait) $=1083$, respectively. Hence, conceding the choice has an advantage. In the wake of watching the business sector and getting more data, it may choose to contribute if the business sector interest ends up being "high", and not to contribute if the interest is "low".
In this illustration, the alternative to hold up gives the firm an extra estimation of 675 .

If $D$ is unknown, the value of immediate investment becomes

$$
\begin{aligned}
\text { NPV (invest now) }= & -7500+0.5\left[\sum_{t=0}^{9} \frac{1}{1.1^{t}} 12 \mathrm{D}\right] \\
& +0.5\left[\sum_{t=0}^{9} \frac{1}{1.1^{t}} 24 D\right] \\
= & -7500+121.68 \mathrm{D}
\end{aligned}
$$

For $D>92.475$, this NPV will be positive, and the customary NPV rule would recommend contribute promptly. Note, then again, that project will wind up being a cash washout if interest ends up being $D_{L}$ as opposed to $D_{H}$. For this situation, the "invest now" option will be productive with no danger of misfortune just if $D>138.705$.

Under symmetric information, we may expect that it is normal learning that the venture will be productive without a doubt if $D>138.705$. Firm A knows this through the estimation we simply did. Firm B can obviously realize this by comparative examination. Firm A ought to expect that firm B will enter the business sector amid first period if firm A not so that the "wait" option will have an estimation of 0 for $D>138.705$. Thus, the hold up's estimation option gets to be

$\mathrm{NPV}($ wait $)= \begin{cases}0 ; & D<74.055 \\ -2.3865+48.345 D ; & 74.055<D<138.705 \\ 0 ; & D>138.705\end{cases}$

For the interest region $D \in(74.055,138.705)$, there is a likelihood that the contender will enter the business sector in the first place, and firm A will lose its option. 


\section{Insights}

When uncertainties exist about the values of key limits, companies often postpone their investment decisions until the key uncertainties have been (fairly) resolved. Although, as we have noticed in real technology investments, companies sometimes do perpetrate investment at an early period despite their ability to postpone their decision. Companies that do so must believe the cost of postponing the investment is greater than the value abandoned from initial exercise (Bacchiega et al. 2012; Briglauer et al. 2013; Koetter and Noth 2013).

In summary, under the NPV, companies do not see the value of waiting, while under the options theory; the value of waiting is engaged but overestimated because of the lack of competition. By correctly including competition in our model, we have an option value that is lower but more practical. The existence of competition abrades the option value of waiting, because chip investments by the competition can abrade or even prevent benefits. Although how precisely competition abrades benefits or prevents investment options will rely on the market framework and each firm's strategic calculation. To engage this, we have to model competition internally by using a game-theoretic method, a topic we are now turning to.

\section{Strategic exercise of growth options under imperfect competition: a game-theoretic model}

In a real world, the investment decisions are affected by a private firm with individual favorites and inconsistent motivations. Besides, each competitor's investment decision is dependent on and sensitive to the other's moves. Game theory provides the method to determine how the players will act when each requests to maximize his own benefit. In such a game-theoretic situation, the value of a real option can be engaged only if it is exercised in a best way, which is fairly dependent on the right expectation of competitors' motions (Flaig et al. 2013; Li et al. 2013).

\section{Model assumptions}

To analyzing competition, we assume (1) competitors make logical tradeoffs in specifying when to exercise their options, so showing optimizing behavior; (2) each player decides by seeing a continuous uncertain state variable and expecting competitor's motions; and (3) the payoffs rely on the resulting equilibrium.

\section{Subgame equilibrium}

\section{The option exercise game}

To highlight the applicability of the method, we concentrate on a special real-world problem: the investment decisions of two firms that are analyzing investing in a new technology. At any time $t$, a firm can spend $C_{i, t}$ to get the technology, for which expected future cash flows dependent on tackling the project have a present value $V_{i, t}$. This is a 2-stage decision.

Normally, $C_{i, t}$ and $I_{i, t}$ are stochastic. We stress the value of $V_{i, t}$ could be notably influenced by the competitor's decisions. So, this two-period model is representative of a wide category of technology investment problems: one first invests in capacities, then gets some extra information, and eventually uses capacities dependent on the displayed information. More accurately, we explain the dynamic option-exercise game below:

- Players: Firm $X$ and firm $Y$.

- Strategies: At the investment period, both firms determine either to invest or postpone in an indivisible technology that requires a rough investment $\operatorname{cost}, C_{i, t}$. If a firm resolves invest, it also needs to determine, at the commercialization period, how much to produce, i.e., a quantity $q_{i}(i=X, Y)$ that maximizes its expected payoff. Therefore each firm has a strategic space $\sigma_{i}=\left(C, D ; q_{i} \mid C\right),(i=X, Y)$.

- Payoffs: The payoff to firm $i$ is a function of the strategies selected by it and its competitor. If both firms $X$ and $Y$ invest without watching each other's decision, they will divide the market as stated by Nash-Cournot equilibrium. If one firm invests first and the other does later, their payoffs will be mentioned through Stackelberg leader-follower equilibrium. If one firm invests first, but the other never does, then the earlier will enjoy a monopoly position. We suppose that a firm's payoff is directly the present value of its profit stream, $s_{i}\left(q_{i}, q_{j}\right)$.

\section{Subgame equilibrium results}

To solve the game, we first get the equilibrium quantities and payoffs for the commercialization period by cost and demand boundaries from an optimization process. These will serve as creating blocks in our following analysis of Nash-Cournot equilibrium under internal competition. Assume the reverse demand function is given by

$P\left(\alpha_{t}, Q\right)=\alpha_{t}-\left(b_{X} q_{X}+b_{Y} q_{Y}\right)$

where $\alpha_{t}$ is the stochastic demand-shift parameter, depicting the uncertainty in market demand, with expected value $E_{0}\left[\alpha_{t}\right]=\alpha_{0}>0$. In this model, $\alpha_{t}$ is supposed to develop as 
stated by a binomial process. $Q=q_{X}+q_{Y}$ is the total quantity on the market, where $q_{X}$ and $q_{Y}$ are the quantities provided by firms $X$ and $Y$ respectively. Without loss of generality, assume $b_{X}=b_{Y}=b$; then (6) becomes $P\left(\alpha_{t}, Q\right)=\alpha_{t}-b\left(q_{X}+q_{Y}\right)$. Show $\Gamma_{i}$ as firm $i$ 's cost function, i.e.,

$\Gamma_{i}\left(q_{i}\right)=\gamma_{i} q_{i}+F$

where $F$ is the fixed cost, and $\gamma_{i}$ is the marginal cost. Without loss of generality, suppose $F=0$.

Concurrent decisions If firms $X$ and $Y$ make their decisions without noticing each other, each would have incomplete information about the other's real motions. This is equal to the situation in which they decide at the same time. Then each firm specifies its optimal quantity to maximize its profit:

$\max _{q_{i}} s_{i}\left(q_{i}, q_{j}\right)=\max _{q_{i}}\left[P\left(\alpha_{t},\left(q_{i}+q_{j}\right)\right) q_{i}-\gamma_{i} q_{i}\right]$

where $s_{i}(i=X, Y)$ is firm $i$ 's profit, and $q_{i}, q_{j}$ are quantities of firms $i$ and $j$ separately. Solving this problem gives the equilibrium quantity:

$q_{i}^{*}=\frac{1}{3 b}\left(\alpha_{i}-2 \gamma_{i}+\gamma_{j}\right)$

The related equilibrium profit for each firm is

$s_{i}=\frac{1}{9 b}\left(\alpha_{t}-2 \gamma_{i}+\gamma_{j}\right)^{2}$

It is easy to show $\frac{\partial s_{i}^{2}\left(q_{i}, q_{j}\right)}{\partial q_{i}^{2}}<0$, so these quantities selects maximize profit. If the two firms have similar cost structures, i.e., $\gamma_{i}=\gamma_{j}=\gamma$ then the equilibrium quantity and profit will be symmetric:

$q_{i}^{*}=q_{j}^{*}=\frac{1}{3 b}\left(\alpha_{t}-\gamma\right)$

$s_{i}=s_{j}=\frac{1}{9 b}\left(\alpha_{t}-\gamma\right)^{2}$

Sequential decisions If two firms move sequentially, the game would begin in an information structure that one firm can notice the other's move. Assume firm $X$ invests first and firm $Y$, on seeing $X$ 's move, follows up. We use the backward method to solve the game. Supposing the leader is already in the market, the follower's decision is

$\max _{q_{Y}} s_{Y}\left(q_{X}^{*}, q_{Y}\right)=\max _{q_{Y}}\left[P\left(\alpha_{t},\left(q_{X}^{*}+q_{Y}\right)\right)-\gamma_{Y}\right] q_{Y}$

Expecting the follower's move, the leader's decision is $\max _{q_{X}} s_{X}\left(q_{X}, q_{Y}^{*}\left(q_{X}\right)\right)=\max _{q_{X}}\left[P\left(\alpha_{t},\left(q_{X}+q_{Y}^{*}\left(q_{X}\right)\right)\right)-\gamma_{X}\right] q_{X}$
Solving the optimization problems in (13) and (14) results the optimal quantities:

$q_{i}^{*}=\frac{1}{2 b}\left(\alpha_{t}-2 \gamma_{t}+\gamma_{j}\right)$
$q_{j}^{*}=\frac{1}{4 b}\left(\alpha_{t}-3 \gamma_{j}+2 \gamma_{i}\right)$

Their related equilibrium profits will then be

$s_{i}=\frac{1}{8 b}\left(\alpha_{t}-2 \gamma_{i}+\gamma_{j}\right)^{2}$

$s_{j}=\frac{1}{16 b}\left(\alpha_{t}-3 \gamma_{j}+2 \gamma_{i}\right)^{2}$

where the subscript $i$ depicts the leader, $j$ the follower.

If the technology is good for multiple periods, we require to reduce the future cash flows. Assuming the operating cash flows $s_{i}$ last $n$ periods, the $\mathrm{NPV}_{i}$ of the profit values will be

$\mathrm{NPV}_{i}=V_{i}-C_{i}=\sum_{i=1}^{n} \frac{s_{t}}{(1+i)^{t}}-C_{i}$

where $s_{i}$ is the operating profit in each period and $i$ is the discount rate. If the technology can produce incomes infinitely, the $\mathrm{NPV}_{i}$ of the constant cash flows would be

$\mathrm{NPV}_{i}=V_{i}-C_{i}=\frac{s_{i}}{i}-C_{i}$

\section{The exercise of growth options under competition}

We now analyze the decision whether to make the strategic investment in the first stage. Without the beginning investment, the two firms would take their existing technologies (and related costs) as given.

Model assumptions

We analyze the investment decision in two conditions: (1) one developing firm has a devoted option to make the beginning investment, but two firms contend directly in the second period; and (2) the option is shared by the two firms, i.e., both firms can invest in the new technology even lessen future costs.

\section{Devoted investment by the developing firm}

Consider first the case where firm $X$ makes no beginning investment, so ex post it has no strategic benefit over its competitor. If both firms select to sell on the market, they encounter the same marginal cost $\gamma$. The equilibrium quantity and profit are precisely the same as in (13-1) and (13-2), with $\gamma$ being returned by $\Gamma$, i.e.,

$q_{i}^{*}=q_{j}^{*}=\frac{1}{3 b}\left(\alpha_{t}-\bar{\gamma}\right)$ 
$s_{i}=s_{j}=\frac{1}{9 b}\left(\alpha_{t}-\bar{\gamma}\right)^{2}$

On the other hand, if firm $X$ makes the strategic investment therefore reducing its marginal cost to $\gamma_{X}=$ $\gamma<\bar{\gamma}=\gamma_{Y}$ the market interaction is influenced by its technological benefit, which is admitted by firm $Y$ when making its output decision. Firms $X$ and $Y$ will select the following quantities, respectively:

$q_{X}^{*}=\frac{1}{3 b}\left(\alpha_{t}-2 \gamma+\bar{\gamma}\right)$

$q_{Y}^{*}=\frac{1}{3 b}\left(\alpha_{t}-2 \bar{\gamma}+\gamma\right)$

Similarly, the related benefits for firms $X$ and $Y$ are, respectively:

$s_{X}^{*}=\frac{1}{9 b}\left(\alpha_{t}-2 \gamma+\bar{\gamma}\right)^{2}$

$s_{Y}^{*}=\frac{1}{9 b}\left(\alpha_{t}-2 \bar{\gamma}+\gamma\right)^{2}$

since $\gamma<\bar{\gamma}$, then

$q_{X}^{*}>q_{Y}^{*}$

$s_{X}^{*}>s_{Y}^{*}$

It is now optimal for firm $Y$ to select a lower quantity, resulting a lower benefit and smaller market share, because of the strategic result of firm $X$ 's investment.

As we can see, the cost benefit got from the strategic investment grows firm $X$ 's benefits and market share. So, the strategic investment creates a competitive advantage. It may be valuable to decay the growth option got by strategic investment in two pieces. First, it results in a lower "unit exercise price" $(\gamma<\bar{\gamma})$ for future expansion. Second, the optimal output $q_{X}^{*}$, "the number of unit production options that are optimally exercised", also grows, as other competitors select to limit their own output to make room for the stronger firm. The optimal investment policy is summarized in the following proposition:

Proposition 1 There exists a supposed demand entrance, such that

$\alpha_{X}^{C^{*}}=\inf \left\{\alpha_{t}: \mathrm{NPV}_{X}^{C} \geq \mathrm{NPV}_{X}^{D}\right\}$

Strategic investment is optimal when demand is more than this entrance.

[Here, we accept the proposition and other presented propositions without proof. For considering the complete proof and further reading of these propositions, please refer to Azevedo and Paxson $(2010,2014)$ and Nishihara (2011)].

\section{Concurrent investments by both firms}

We now expand the basic model in the last section of the case when neither firm likes to devote protection (license) on the strategic investment, meaning the investment opportunity is open to all competitors.

Model assumptions

Both firms $X$ and $Y$ can invest in the new technology to lessen their future costs to $\gamma$. The final market results could be a monopoly, symmetric or asymmetric Cournot equilibrium, or no investment. Figure 3 shows the four possible combinations: $(I, I),(I, D),(D, I),(D, D)$ where $I$ means "invest" and $D$ "defer".

Particularly, the first-stage investment game may result in a second-period commercialization period with the following possible results: symmetric but lower costs for both firms (both invested), asymmetric production costs (one firm invested) and the same the existing state of affairs costs of the existing technology (neither invested in the new technology; Huang and Behara 2013).

We have the following result:

Proposition 2 The equilibria to exercise the investment option are

$(I, I), \quad$ if $\alpha>\gamma+3 \sqrt{b i C}$

$(D, D), \quad$ if $\alpha \leq \gamma+2 \sqrt{b i C}$

Mixed strategy $(I, \quad D)$ or $(D, \quad I), \quad$ if $\gamma+2 \sqrt{b i C}<$ $\alpha \leq \gamma+3 \sqrt{b i C}$.

That is, optimal investment strategy is concurrent investment by both firms if $\alpha>\gamma+3 \sqrt{b i C}$, mixed strategy by either firm if $\gamma+2 \sqrt{b i C}<\alpha \leq \gamma+3 \sqrt{b i C}$, and no investment by both if $\alpha \leq \gamma+2 \sqrt{b i C}$. The demand entrance for concurrent investment is

$\alpha^{I I^{*}}=\gamma+3 \sqrt{b i C}$

\section{Multi-period model}

We use a multi-period game tree structure as a thoroughform representation of the option exercise game. Firms $X$ and $Y$ determine either to invest $(I)$ or defer $(D)$ in each period. Then Nature $(N)$, which shows the external uncertainty, determines the market demand will be either moved up to $u \alpha$ or down to $d \alpha$ similar to a binomial process, where $u$ and $d$ are the binomial parameters. On noticing the decisions made in the previous period and developing the market demand, each firm determines once more to invest or defer in the next period. The game can continue as many periods as required. In a multi-period setting, dynamic programming and backward induction allow us with the 
Fig. 3 Concurrent investment in growth options (the dotted line shows the information structure that firm $Y$ cannot see the firm's action)

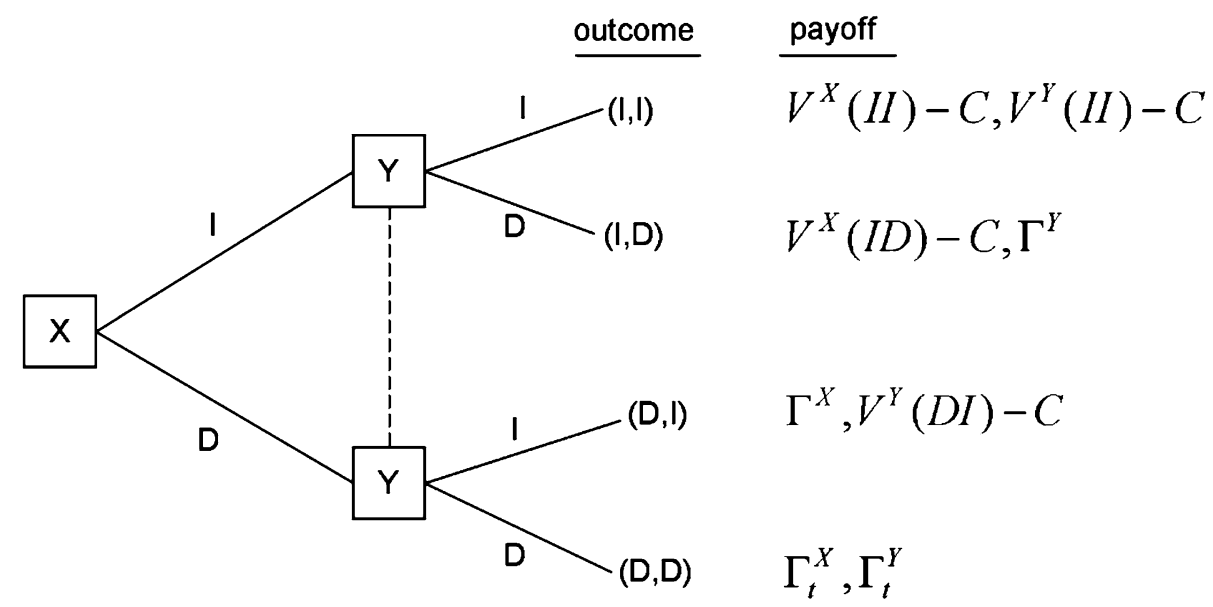

mathematical tools to solve multiple period problems (Huang and Qiao 2012). Specially, the value function of the investment project can be shown by the "Bellman" equation:

$V(x)=\max \left\{E\left[s_{i}\right]-C, \frac{1}{1+i} E\left[V^{\prime}(x) \mid x\right]\right\}$

where $V(x)$ is the value of the investment project, $x$ the state variable, $C$ the investment cost, $s$ the expected cash flows dependent on the investment has been made, and $i$ the discount rate. $V^{\prime}(x)$ is the future extension value dependent on the present state variable.

The first term in (26) depicts the value of exercising the option, while the second term chooses the value of extension (i.e., holding the option). In every period, each firm would distinguish these two terms, taking analysis what the other firm would do.

\section{Two-period equilibrium}

We now appeal the dynamic structure in the two-period case, where the option to make the strategic investment stays obtainable for two periods. The demand entrance and the investment strategy are summarized in the following proposition:

Proposition 3 Both firms exercise their options concurrently when the expected demand is more than the entrance:

$\alpha_{0}^{2-p^{*}}=e^{\sigma \sqrt{\Delta t}}(\gamma+3 \sqrt{b i C})$

Investment entrance (27) specifies that $\alpha_{0}^{2-p^{*}}$ is an increasing function of the volatility of the market demand, interest rate, marginal cost, and the investment cost. So firms would incline to wait longer if the market is more unpredictable, if the technology costs more to install, or if the cost demotion is small. Reasons like lower uncertainty, shorter option life, and more thorough competition would incline to lower the investment entrance. A lower investment entrance suggests the lower option value of waiting and more violent investment strategy. Note that

$e^{\sigma \sqrt{\Delta t}}>1$

Consequently

$$
\begin{aligned}
\alpha_{0}^{I I^{*}}(1 \text { period }) & =\gamma+3 \sqrt{b i C}<\alpha_{0}^{2-p^{*}}(2 \text { period }) \\
& =e^{\sigma \sqrt{\Delta t}}(\gamma+3 \sqrt{b i C})
\end{aligned}
$$

where $\sigma$ measures the volatility of the market uncertainty. Higher volatility $\sigma$ suggests a higher investment entrance, $\alpha^{*}$. So, if the uncertainty is high, firms incline to wait longer. In other words, higher volatility suggests greater option value to defer investment. From (29), we have the following corollary:

Corollary The investment entrance of the two periods is higher than that of one period.

\section{More periods}

When the game lasts $3,4,5, \ldots$ and $n$ periods, the same method appeals often. One can always work backwards all the way to the beginning period. One just roll the equilibrium payoffs of the period $t$ back to the previous period $(t-1)$ until one achieves the present period of the game. Relied on the $\mathrm{NPV}_{i}$ 's of different chances, each firm resolves its best strategies. Attention the game revives itself if it gets a $(D, D)$ division.

\section{Effects of competition on investment}

The option value of waiting in a two-period game is 


$$
O= \begin{cases}\frac{q}{1+i}\left[\frac{\left(u \alpha_{0}-\gamma\right)^{2}}{9 i b}-C_{0}(1+i)\right], & \alpha_{0} \leq \gamma+3 \sqrt{i b C_{o}} \\ \frac{q\left(u \alpha_{0}-\gamma\right)^{2}}{9 i b}-\frac{\left(\alpha_{0}-\gamma\right)^{2}}{9 i b}+(C-q) C_{0}, & \alpha_{0}>\gamma+3 \sqrt{i b C_{0}}\end{cases}
$$

where $q$ shows the probability in a risk-neutral world, $i$ the discount rate, and $u$ the binomial factor "up". Equation (30) illustrates the option value is a growing function of $u$ and $q$, meaning the firms would be more possible to wait if the extent and chance of demand rising motion are larger than if they are small.

It can be proved the option value under competition in (30) is lower than that without competition (i.e., the option value of waiting for a monopoly as in Dixit and Pindyck 1994). That is, competition abrades the option value. The real options literature has explored the option value of waiting for a firm when payoffs are stochastic and investment irreparable. It has been illustrated in these studies that firms will typically delay investing until well after the point at which supposed discounted benefits identical beginning costs. In so doing, they use the option value of waiting. Although, the option value of waiting may have been overestimated when the risk of competitive abrasion or prevention is excluded (Smit and Trigeorgis 2006; Aleksandrov et al. 2013; Levaggi et al. 2012; Podoynitsyna et al. 2013). Certainly, the option value without competition is only an upper limit of the option value with competition. So, including competition is important to get a practical option valuation.

\section{Discussions and extensions}

\section{New and existing technologies}

The vital benefit of the investment is a more logical technology with lower marginal cost. That is, the marginal cost of selling one unit to the market will be lower with the investment than that without the investment. As a result, the first-period investment may result in a second-period competitive benefit about its competitor, with the following possible results: symmetric but lower costs for both firms (if both invested), asymmetric production costs (if one firm invested), and the same base-case costs related to the existing technology (if neither invested in the new technology).

In the above consideration, we have supposed there was an existing technology. Firms invest to improve or return the old technology. Another case is there is no existing technology so far, firms invest to enter this new product market. Without the new technology, firms would have to stay out the market and make zero income.
These two conditions can be summarized more accurately. The option value of continuation, $\Gamma$, is either zero or positive. That is,

$\Gamma= \begin{cases}0 & \text { no prior tech exist } \\ \frac{1}{9 i b}\left(\alpha_{t}-\bar{\gamma}\right)^{2} & \text { there is an existing tech }\end{cases}$

\section{Asymmetric competition}

We supposed earlier that, for both firms, the investment would result the same benefit (cost decline), i.e., the technologies got through beginning investment have the identical marginal costs. What if the investments may result in technologies with different costs?

Consider the cost first. Assume $\gamma_{X}>\gamma_{Y}$, from (21) and Proposition 3, we have

$$
\begin{aligned}
& s_{X}^{*}=\frac{1}{9 b}\left(\alpha_{t}-2 \gamma_{X}+\gamma_{Y}\right)^{2}<s_{Y}^{*}=\frac{1}{9 b}\left(\alpha_{t}-2 \gamma_{Y}+\gamma_{X}\right)^{2} \\
& \alpha_{X}^{*}=e^{\sigma \sqrt{\Delta t}}\left(\Gamma_{X}+3 \sqrt{b i C}\right)>\alpha_{Y}^{*}=e^{\sigma \sqrt{\Delta t}}\left(\gamma_{Y}+3 \sqrt{b i C}\right)
\end{aligned}
$$

That is, if to implement the new technology results in a lower cost for firm $Y$ than for firm $X$, then firm $Y$ would have greater motivation to invest in the technology first. Also, if this cost distinction grows big enough to the extent that

$\alpha_{Y}^{*}=e^{\sigma \sqrt{\Delta t}}\left(\gamma_{Y}+3 \sqrt{b i C}\right)<e^{\sigma \sqrt{\Delta t}}\left(\gamma_{X}+2 \sqrt{b i C}\right)$

then firm $Y$ will invest first still in the middle area. Consequently the diversified investment strategy, $(I, D)$ and $(D$, $I)$, is substituted by $(D, I)$, a sequential investment strategy where the firm with lower marginal cost (firm $Y$ in this case) will invest first.

Second, the investment may result in different quality of product or service, as evaluated by the parameter $b$, in (7). Assuming $b_{X}>b_{Y}$ meaning firm $Y$ 's product is better recognized by the customers, the investment would result in a higher payoff function, and lower investment entrance, for firm $Y$. Eventually, all these factors are normally integrated. It is hard to see that a company with higher marginal cost and lower quality can continue in the market. Generally a firm with higher cost may like a better product.

\section{Asymmetric information}

Until now we have limited our consideration to option exercise under an information structure in which firms have symmetric information. Although in real world, investment and competition often happen in an environment of information asymmetry. That is, companies may have 
incomplete and asymmetrically scattered information on parameters like development costs or market demands. In this section, we emphasize on information asymmetry and its effect on option exercise. In an option-exercise game with full information, the firms' payoff functions are general knowledge. In a game with incomplete information, in contrast, at the minimum one firm is unsure about another firm's payoff or cost functions. An equilibrium pricing method must be used in a world of asymmetric information. The equilibrium method moderates the tradability suppositions required for arbitrage pricing (Batabyal 2012; Schwienbacher 2013). To avoid further problem, we assume risk neutrality, so prices are specified by discounting expected values, where the supposition is dependent on the obtainable information. Besides, we suppose the investment project under consideration is a small part of the firm's total assets.

Given the role of asymmetric information, changing the full-information supposition will add notable realism to the models of option exercise and technology investments. A few recent studies involve asymmetric information in their models. For example, Grenadier (1999) shows how information externalities may be created through noted option exercise decisions. Nadiminti et al. (2002) analyze intrafirm resource assignment under asymmetric information and negative externalities. These studies represent the fast evolution of the field.

\section{Model assumptions of asymmetric information}

We define the asymmetric information as follows:

(1) Information is incomplete and asymmetric. Firm $X$ knows its own cost function,

$\Gamma_{X}\left(q_{X}\right)=\gamma_{X} q_{X}$

but has only incomplete information about firm $Y^{\prime} \mathrm{s}$ cost function. The following probability distribution shows firm $X$ 's opinion about firm $Y$ 's cost function:

$\Gamma_{Y}\left(q_{Y}\right)= \begin{cases}\gamma_{H} q_{Y} & \text { with probability } \theta \\ \gamma_{L} q_{Y} & \text { with probability } 1-\theta\end{cases}$

where $\gamma_{L}<\gamma_{X}<\gamma_{H}$ (to avoid unimportant cost benefit).

(2) Firm $Y$ realizes both firms' cost functions, therefore has better information. Firm $Y$ could have just created a new technology, and its cost has not got public information so far. On the other hand, firm $X$ continues to use the traditional technology of which the cost is generally known.

(3) All of this is usual knowledge: firm $X$ realizes that firm $Y$ has better information, firm $Y$ knows that firm $X$ realizes this, and so on.
(4) The inverse demand function and the stochastic demand-shift parameter are described.

In such a game with incomplete information, we say that firm $Y$ has two possible types, $\gamma_{L}$ and $\gamma_{H}$ or its type space is $T_{Y}=\left\{\gamma_{L}, \gamma_{H}\right\}$. Firm $X$ 's type space is simply $T_{X}=\left\{\gamma_{X}\right\}$. Firm $Y$ realizes its own type besides firm $X$ 's type, while firm $X$ is uncertain about the $Y$ 's type. Formally,

$$
\begin{aligned}
& P_{X}\left(t_{Y}=c_{H} \mid t_{X}=\gamma_{X}\right)=\theta, \\
& P_{X}\left(t_{Y}=c_{L} \mid t_{X}=\gamma_{X}\right)=1-\theta
\end{aligned}
$$

\section{Sequential exercises}

The sequencing of exercises is critical for an option-exercise game under asymmetric information, because decisions about exercise (and nonexercise) may release private information, as one firm can notice the other. Firms can gather information by moving later than others. The order of moves suggests each firm's calculated tradeoff between the strategic result of exercising early and the informational benefit of waiting to learn competitors' individual information through their disclosed actions. In the literature, the sequencing of actions has been normally supposed to be pre-determined. In contrast, we permit the sequencing of exercise to be internally mentioned through agents' optimizing decisions. Two sequences are possible:

Sequence 1 The less informed firm $(X)$ moves first and the more informed firm $(Y)$ follows.

In the spirit of backward induction, we first solve the follower's decision. Supposing the leader has already decided $q_{X}^{*}$, the follower will choose $q_{Y}$ to maximize its profit dependent on its cost structures, i.e.,

$$
\begin{aligned}
& \max _{q_{Y}\left(\gamma_{H}\right)} s_{Y}\left(q_{X}^{*}, q_{Y}, \gamma_{H}\right) \\
& =\max _{q_{Y}\left(\gamma_{H}\right)}\left[P\left(\alpha_{t},\left(q_{X}^{*}\left(q_{Y}\right)+q_{Y}\left(\gamma_{H}\right)\right)\right)-\gamma_{H}\right] q_{Y}\left(\gamma_{H}\right) \\
& \max _{q_{Y}\left(\gamma_{L}\right)} s_{Y}\left(q_{X}^{*}, q_{Y}, \gamma_{L}\right) \\
& =\max _{q_{Y}\left(\gamma_{L}\right)}\left[P\left(\alpha_{t},\left(q_{X}^{*}\left(q_{Y}\right)+q_{Y}\left(\gamma_{L}\right)\right)\right)-\gamma_{L}\right] q_{Y}\left(\gamma_{L}\right)
\end{aligned}
$$

The leader's decision, expecting firm $Y$ 's above move, is to select $q_{X}$ to maximize its payoff:

$$
\begin{aligned}
& \max _{q_{X}} s_{X}\left(q_{X}, q_{Y}\right) \\
& =\max _{q_{X}}\left\{\theta\left[P\left(\alpha_{t},\left(q_{X}+q_{Y}^{*}\left(\Gamma_{H}\right)\right)\right)-c_{X}\right] q_{X}\right. \\
& \left.\quad+(1-\theta)\left[P\left(\alpha_{t},\left(q_{X}+q_{Y}^{*}\left(\gamma_{L}\right)\right)\right)-c_{X}\right] q_{X}\right\}
\end{aligned}
$$

The solutions to (39)-(41) are, respectively

$q_{X}^{*}=\frac{1}{2 b}\left[\alpha_{t}-2 \gamma_{X}+\theta \gamma_{H}+(1-\theta) \gamma_{L}\right]$ 


$$
\begin{aligned}
& q_{Y}^{*}\left(\gamma_{H}\right)=\frac{1}{4 b}\left(\alpha_{t}-3 \gamma_{H}+2 \gamma_{X}\right)+\frac{1-\theta}{4 b}\left(\gamma_{H}-\gamma_{L}\right) \\
& q_{Y}^{*}\left(\gamma_{L}\right)=\frac{1}{4 b}\left(\alpha_{t}-3 \gamma_{L}+2 \gamma_{X}\right)-\frac{\theta}{4 b}\left(\gamma_{H}-\gamma_{L}\right)
\end{aligned}
$$

Then the correlating equilibrium benefits are

$s_{X}^{*}=\frac{1}{8 b}\left[\alpha_{t}-2 \gamma_{X}+\theta \gamma_{H}+(1-\theta) \gamma_{L}\right]^{2}$

$s_{Y}^{*}\left(\gamma_{H}\right)=\frac{1}{16 b}\left[\left(\alpha_{t}-3 \gamma_{H}+2 \gamma_{X}\right)+(1-\theta)\left(\gamma_{H}-\gamma_{L}\right)\right]^{2}$

$s_{Y}^{*}\left(\gamma_{L}\right)=\frac{1}{16 b}\left[\left(\alpha_{t}-3 \gamma_{L}+2 \gamma_{X}\right)-\theta\left(\gamma_{H}-\gamma_{L}\right)\right]^{2}$

Sequence 2 The more informed firm $(Y)$ moves first and the less informed firm $(X)$ follows.

If the firm with individual information moves first, the follower would have an opportunity to conclude the leader's individual information through disclosed effects. More precisely, firm $X$ would notice $Y$ 's quantity selects $q_{Y}^{*}\left(\gamma_{H}\right), q_{Y}^{*}\left(\gamma_{L}\right)$, and conclude firm $Y$ 's cost functions, $\gamma_{H}$ or $\gamma_{L}$ properly. The more informed firm would disclose its individual information through its exercise decisions. Because of this information disclosure, the information asymmetry may be reduced.

On learning firm $Y^{\prime}$ 's individual information about its cost function, firm $X$ selects its quantity to maximize its benefit. The learning could disclose two possible results: firm $Y$ 's cost could be high $\left(\gamma_{Y}=\gamma_{H}\right)$ and low $\left(\gamma_{Y}=\gamma_{L}\right)$. Depending on that firm $X$ learned $\gamma_{Y}=\gamma_{H}$, firm $X$ 's decision would be

$\max _{q_{X}} s_{X}\left(q_{X}, q_{Y}^{*}\left(\gamma_{H}\right)\right)=\max _{q_{X}}\left[P\left(\alpha_{t},\left(q_{X}+q_{Y}^{*}\left(\gamma_{H}\right)\right)\right)-\gamma_{X}\right] q_{X}$

As well, dependent on that firm $X$ learned $\gamma_{Y}=\gamma_{L}$, firm $X$ 's decision would be

$\max _{q_{X}} s_{X}\left(q_{X}, q_{Y}^{*}\left(\gamma_{L}\right)\right)=\max _{q_{X}}\left[P\left(\alpha_{t},\left(q_{X}+q_{Y}^{*}\left(\gamma_{L}\right)\right)\right)-\gamma_{X}\right] q_{X}$

Expecting firm $X$ 's above reaction, firm $Y$ solves for $q_{Y}\left(\gamma_{H}\right)$ when its true cost is $\gamma_{H}$, i.e.,

$\max _{q_{Y}\left(\gamma_{H}\right)} s_{Y}\left(q_{X}^{*}, q_{Y}\left(\gamma_{H}\right)\right)=\max _{q_{Y}\left(\gamma_{H}\right)}\left[P\left(\alpha_{t},\left(q_{X}^{*}\left(q_{Y}\right)+q_{Y}\left(\gamma_{H}\right)\right)\right)-\gamma_{H}\right] q_{Y}\left(\gamma_{H}\right)$

By the similar analysis, firm $Y$ solves for $q_{Y}\left(\gamma_{L}\right)$ when its true cost is $\gamma_{L}$, i.e.,

$\max _{q_{Y}\left(\gamma_{L}\right)} s_{Y}\left(q_{X}^{*}, q_{Y}\left(\gamma_{L}\right)\right)=\max _{q_{Y}\left(\gamma_{L}\right)}\left[P\left(\alpha_{t},\left(q_{X}^{*}\left(q_{Y}\right)+q_{Y}\left(\gamma_{L}\right)\right)\right)-\gamma_{L}\right] q_{Y}\left(\gamma_{L}\right)$
Solving the optimization problems in (46)-(49) results the below equilibrium quantities:

Conditional on $\gamma_{Y}=\gamma_{H}$,

$q_{X}^{*}\left(\gamma_{H}\right)=\frac{1}{4 b}\left(\alpha_{t}-3 \gamma_{X}+2 \gamma_{H}\right)$

$q_{Y}^{*}\left(\gamma_{H}\right)=\frac{1}{2 b}\left(\alpha_{t}-2 \gamma_{H}+\gamma_{X}\right)$

and dependent on $\gamma_{Y}=\gamma_{L}$,

$q_{X}^{*}\left(\gamma_{L}\right)=\frac{1}{4 b}\left(\alpha_{t}-3 \gamma_{X}+2 \gamma_{L}\right)$

$q_{Y}^{*}\left(\gamma_{L}\right)=\frac{1}{2 b}\left(\alpha_{t}-2 \gamma_{L}+\gamma_{X}\right)$

The similar equilibrium benefits are, respectively

$s_{X}^{*}\left(\gamma_{H}\right)=\frac{1}{16 b}\left(\alpha_{t}-3 \gamma_{X}+2 \gamma_{H}\right)^{2}$

$s_{Y}^{*}\left(\gamma_{H}\right)=\frac{1}{8 b}\left(\alpha_{t}-2 \gamma_{H}+\gamma_{X}\right)^{2}$

$s_{X}^{*}\left(\gamma_{L}\right)=\frac{1}{16 b}\left(\alpha_{t}-3 \gamma_{X}+2 \gamma_{L}\right)^{2}$

$s_{Y}^{*}\left(\gamma_{L}\right)=\frac{1}{8 b}\left(\alpha_{t}-2 \gamma_{L}+\gamma_{X}\right)^{2}$

where (54) and (55) are conditional on $\gamma_{Y}=\gamma_{H}$ while (56) and (57) are dependent on $\gamma_{Y}=\gamma_{L}$.

\section{Equilibrium analysis}

When information is asymmetric, equilibrium exercise may be sequential, with the more informed firm exercising first and permitting the less informed to free sit on the information expressed by the exercise (or failure to exercise). Although, the information asymmetry is furthermore difficult by the presence of cost asymmetry. The firm with lower cost may have lower investment entrance and higher inducements to move early (Genc and Zaccour 2013). To make easier resemblance, we achieve the equilibrium analysis for two situations: (1) we first suppose that firm $Y$ realizes that its true cost is $\gamma_{Y}=\gamma_{L}$ (firm $X$ does not realize this) in "Equilibrium under asymmetric information $\left(\gamma_{Y}=\gamma_{L}\right)$ " section; (2) we then turn to situating $\gamma_{Y}=\gamma_{H}$ in "Equilibrium under asymmetric information $\left(\gamma_{Y}=\gamma_{H}\right)$ " section.

Equilibrium under asymmetric information $\left(\gamma_{Y}=\gamma_{L}\right)$

If firm $Y$ realizes that its true cost is low (again firm $X$ does not realize this because of information asymmetry), firm $Y$ would exercise its option first to engage the payoff 
benefit. The entire demand range is divided into three areas, thus area $I$, waiting region $(D, D)$, area $I I$, sequential investment region $(D, I)$ and area $I I I$, simultaneous investment region $(I, I)$. This result is formalized in the following proposition:

Proposition 4 (Equilibrium under asymmetric information when $\gamma_{Y}=\gamma_{L}$ ) Under asymmetric information, the option-exercise game has three equilibria

$$
\begin{gathered}
(D, D), \alpha<2 \gamma_{L}-\gamma_{X}+\sqrt{8 b i C} \\
(D, I), 2 \gamma_{L}-\gamma_{X}+\sqrt{8 b i C} \leq \alpha<2 \gamma_{X}-\theta \gamma_{H} \\
-(1-\theta) \gamma_{L}+3 \sqrt{b i C} \\
(I, I), \alpha \geq 2 \gamma_{X}-\theta \gamma_{H}-(1-\theta) \gamma_{L}+3 \sqrt{b i C}
\end{gathered}
$$

Proposition 4 illustrates that when asymmetry exists and demand is in area II equilibrium exercise will be sequential and instructive. With asymmetric information, the option exercise is $(D, I)$; the more informed firm moves first and engages higher benefits from being a leader. The less informed firm selects to wait and free sit on the information expressed by the leader's exercise. This permits the follower to conclude the leader's individual information through noticed exercise of options. So, in this equilibrium, the leader gets payoff compensation and the follower gets informational benefits.

\section{Equilibrium under asymmetric information $\left(\gamma_{Y}=\gamma_{H}\right)$}

If firm $Y$ knows that its true cost is high (remember firm $X$ does not know this because of information asymmetry), firm $Y$ would become unwilling to exercise its option first because doing so may disclose to its competitor that it is really a high cost (therefore weak) player. This normally guides us to feel the equilibrium $(D, I)$ in area $I I$ may no longer exist.

It appears, although, the equilibrium $(D, I)$ still exists, but with more restrictive situations than in the $\gamma_{Y}=\gamma_{L}$ case. This result is formalized in the following proposition.

Proposition 5 (Equilibrium under asymmetric information when $\gamma_{Y}=\gamma_{L}$ ) Under asymmetric information the option-exercise game may have the following the arealibria: $(D, D)$ in area $I$ and $(I, I)$ in area III. In area II, the equilibrium is sequential $(D, I)$ if the following situations are encountered:

$$
\begin{aligned}
\gamma_{X}>\max \left\{\frac{1}{3}\left(2 \gamma_{H}+\gamma_{L}+\theta\left(\gamma_{H}-\gamma_{L}\right)\right),\left(\gamma_{H}-\left(1-\frac{\sqrt{2}}{2}\right) \sqrt{b i C}\right)\right\} \\
(1-\theta)\left(\gamma_{H}-\gamma_{L}\right)<2(3-\sqrt{8}) \sqrt{b i C}
\end{aligned}
$$

The equilibrium may be $(I, D)$, in other respects. The three areas are explained as

$$
\begin{aligned}
C, \alpha<\min \{( & \left.2 \gamma_{H}-\gamma_{X}+\sqrt{8 b i C}\right),\left(2 \gamma_{X}-\theta \gamma_{H}-(1-\theta) \gamma_{L}\right. \\
+\sqrt{8 b i C})\} & \\
I I I, \alpha \geq \max \{ & \left(2 \gamma_{X}-\theta \gamma_{H}-(1-\theta) \gamma_{L}+3 \sqrt{b i C}\right), \\
& \left.\left(2 \gamma_{H}-\gamma_{X}-\frac{1-\theta}{2}\left(\gamma_{H}-\gamma_{L}\right)+3 \sqrt{b i C}\right)\right\}
\end{aligned}
$$

$I I$, the area between regions $I$ and $I I I$

\section{Comparative statics}

We have considered the existence and the economic rationality of equilibria for the two conditions above. It is interesting to distinguish the equilibrium area under incomplete information to those under full information. This will also permit us to measure the results of asymmetric information.

For firm $X$, the entrance demand levels with full information would be

$$
\begin{aligned}
\alpha_{N S}^{*}\left(X \mid \gamma_{L}, F I\right) & =2 \gamma_{X}-\gamma_{L}+3 \sqrt{b i C} \\
\alpha_{N S}^{*}\left(X \mid \gamma_{H}, F I\right) & =2 \gamma_{X}-\gamma_{H}+3 \sqrt{b i C}
\end{aligned}
$$

With incomplete information, the relating entrance (from Proposition 4) becomes

$\alpha_{N S}^{*}(X \mid \theta, I I)=2 \gamma_{X}-\gamma_{L}-\theta\left(\gamma_{H}-\gamma_{L}\right)+3 \sqrt{b i C}$

where $F I$ denotes "full information" and $I I$ "incomplete information". $\alpha_{N S}^{*}\left(X \mid \gamma_{H}, F I\right)$ stands for the entrance level that firm $X$ will invest under Nash equilibrium, dependent on firm $X$ 's having full information and assuming firm $Y$ 's $\operatorname{cost}$ is $\gamma_{H}$ with a probability $\theta=1$. As well, $\alpha_{N S}^{*}(X \mid \theta, I I)$ depicts the entrance level that firm $X$ will invest under Nash equilibrium, depending on firm $X$ 's having incomplete information and assuming firm $Y^{\prime} \mathrm{s}$ cost is $\gamma_{H}$ with probability $\theta$. From (61), we have

$\frac{\partial \alpha_{N S}^{*}(X \mid \theta, I I)}{\partial \theta}=-\left(\gamma_{H}-\gamma_{L}\right)<0$

Thus $\alpha_{N S}^{*}(X \mid \theta, I I)$ is a reducing function of $\theta$, suggesting that firm $X$ would invest at a lower entrance (so more violently) if it has a stronger opinion that its competitor is a high cost player. This is regular with what we have learned in previous sections. It can be confirmed that

$\alpha_{N S}^{*}\left(X \mid \gamma_{H}, F I\right)<\alpha_{N S}^{*}\left(X \mid \gamma_{L}, F I\right)$

As a consequence, the full-information entrance levels are directly specific cases of the asymmetric-information entrance. More generally, the full-information equilibrium 
is a special case of the asymmetric-information equilibrium. From firm $Y^{\prime}$ s view, the entrance levels are

$$
\begin{aligned}
\alpha_{N S}^{*}\left(Y \mid \gamma_{L}, I I\right)= & 2 \gamma_{L}-\gamma_{X}+\frac{\theta}{2}\left(\gamma_{H}-\gamma_{L}\right) \\
& +3 \sqrt{b i C}>\alpha_{N S}^{*}\left(Y \mid \gamma_{L}, F I\right) \\
= & 2 \gamma_{L}-\gamma_{X}+3 \sqrt{b i C} \\
\alpha_{N S}^{*}\left(Y \mid \gamma_{H}, I I\right)= & 2 \gamma_{H}-\gamma_{X}-\frac{1-\theta}{2}\left(\gamma_{H}-\gamma_{L}\right) \\
& +3 \sqrt{b i C}<\alpha_{N S}^{*}\left(Y \mid \gamma_{H}, F I\right) \\
= & 2 \gamma_{H}-\gamma_{X}+3 \sqrt{b i C}
\end{aligned}
$$

In a world of asymmetric information, $\alpha_{N S}^{*}\left(Y \mid \gamma_{L}, I I\right)$ is greater than $\alpha_{N S}^{*}\left(Y \mid \gamma_{L}, F I\right)$ and $\alpha_{N S}^{*}\left(Y \mid \gamma_{H}, I I\right)$ is less than $\alpha_{N S}^{*}\left(Y \mid \gamma_{H}, F I\right)$. The difference is larger if the information asymmetry is notable (as measured by $\theta$ and $\left.\Delta \gamma=\gamma_{H}-\gamma_{L}\right)$. This happens because firm $Y$ not only adjusts its entrance to its own cost but also replies to the fact that firm $X$ has incomplete information and thus cannot do the same. If firm $Y^{\prime}$ s costs are high, for example it waits longer and invest at an entrance that is higher than firm $X$ would do if it knew with full information firm $Y^{\prime}$ s costs to be high.

\section{Conclusions}

Most of the real options literature has concentrated on market environments without strategic interactions. On the other hand, the industrial organization literature endogenizes market structure; so far it usually neglects uncertainty and so the option value of flexibility. Considering the linkage effects of both uncertainty and competition, this paper extends a method for assessing technology investment decisions in an oligopolistic market structure. It combines the game-theoretic models of strategic market interactions with a real options approach to investment under uncertainty, and gives an improved comprehension of the results of uncertainty and competition on the strategic exercise of real options inserted in technology investments.

Through expanding an equilibrium model of a dynamic investment game, the paper makes several contributions. First, showing that investment strategies critically rely on competitive interactions, the study improves our comprehension of the linkage effects of competition and uncertainty on investment decisions. We have best investment policies and vital investment entrances. Besides, we have also taken analysis of different information structures.

One of the restrictions of the paper is the work is mostly methodological and theoretical-appealing economic models to technology investment under both uncertainty and competition. Although we have tried to link the theory to fact, the work could be improved by adding some practical elements. However, the results got in the paper could be used to form theories to carry out practical testing.

Open Access This article is distributed under the terms of the Creative Commons Attribution 4.0 International License (http://crea tivecommons.org/licenses/by/4.0/), which permits unrestricted use, distribution, and reproduction in any medium, provided you give appropriate credit to the original author(s) and the source, provide a link to the Creative Commons license, and indicate if changes were made.

\section{References}

Albuquerque R, Miao J (2014) Advance information and asset prices. J Econ Theory. doi:10.1016/j.jet.2013.06.001

Aleksandrov N, Espinoza R, Gyurkó L (2013) Optimal oil production and the world supply of oil. J Econ Dyn Control 37(7):1248-1263. doi:10.1016/j.jedc.2013.01.015

Alexandrov A, Deb J (2012) Price discrimination and investment incentives. Int J Ind Organ 30(6):615-623. doi:10.1016/j.ijin dorg.2012.07.001

Amram M, Kulatilaka N (1999) Real options: managing strategic investment in an uncertain world. Harvard Business School, Cambridge, MA

Azevedo AF, Paxson DA (2010) Real options game models: a review. Real Options. http://realoptions.org/papers2010/109.pdf

Azevedo A, Paxson D (2014) Developing real option game models. Eur J Oper Res 237(3):909-920

Bacchiega E, Randon E, Zirulia L (2012) Strategic accessibility competition. Res Econ 66(2):195-212. doi:10.1016/j.rie.2011. 12.001

Batabyal AA (2012) Project financing, entrepreneurial activity, and investment in the presence of asymmetric information. $\mathrm{N} \mathrm{Am} \mathrm{J}$ Econ Finance 23(1):115-122. doi:10.1016/j.najef.2011.11.006

Benaroch M, Kauffman RJ (1999) A case for using real options pricing analysis to evaluate information technology project investments. Inf Syst Res 10(1):70-86

Berghman L, Matthyssens P, Vandenbempt K (2012) Value innovation, deliberate learning mechanisms and information from supply chain partners. Ind Mark Manag 41(1):27-39. doi:10. 1016/j.indmarman.2011.11.014

Berghout E, Tan C-W (2013) Understanding the impact of business cases on IT Investment decisions: an analysis of municipal e-government projects. Inf Manag. doi:10.1016/j.im.2013.07.010

Bos JWB, Kolari JW, van Lamoen RCR (2013) Competition and innovation: evidence from financial services. J Bank Finance 37(5):1590-1601. doi:10.1016/j.jbankfin.2012.12.015

Briglauer W, Ecker G, Gugler K (2013) The impact of infrastructure and service-based competition on the deployment of next generation access networks: recent evidence from the European member states. Inf Econ Policy 25(3):142-153. doi:10.1016/j. infoecopol.2012.11.003

Brynjolfsson E (1993) The productivity paradox of information technology. Commun ACM 36(12):66-77

Chaton C, Guillerminet M-L (2013) Competition and environmental policies in an electricity sector. Energy Econ 36:215-228. doi:10.1016/j.eneco.2012.08.014

Clemons EK Evaluation of strategic investments in information technology. Paper presented at the Communications of the ACM

Dewan S, Kraemer K (1998) Information technology and productivity: evidence from country level data. Graduate School of Management, University of California 
Dimitrios NK, Sakas DP, Vlachos DS (2013) Analysis of strategic leadership models in information technology. Proc Soc Behav Sci 73:268-275. doi:10.1016/j.sbspro.2013.02.052

Dixit AK, Pindyck RS (1994) Investment under uncertainty. Princeton University Press, Princeton

Dos Santos B (1991) Justifying investments in new information technologies. Krannert Graduate School of Management, Purdue University

Fernandes R, Gouveia B, Pinho C (2013) A real options approach to labour shifts planning under different service level targets. Eur J Oper Res 231(1):182-189. doi:10.1016/j.ejor.2013.05.008

Flaig D, Rubin O, Siddig K (2013) Imperfect competition, border protection and consumer boycott: the future of the dairy industry in Israel. J Policy Model 35(5):838-851. doi:10.1016/j.jpolmod. 2013.01.001

Gao X, Zhong W, Mei S (2013) A differential game approach to information security investment under hackers' knowledge dissemination. Oper Res Lett 41(5):421-425. doi:10.1016/j.orl. 2013.05.002

Genc TS, Zaccour G (2013) Capacity investments in a stochastic dynamic game: equilibrium characterization. Oper Res Lett 41(5):482-485. doi:10.1016/j.orl.2013.05.012

Grenadier SR (1999) Information revelation through option exercise. Rev Financ Stud 12(1):95-129

Huang CD, Behara RS (2013) Economics of information security investment in the case of concurrent heterogeneous attacks with budget constraints. Int $\mathrm{J}$ Prod Econ 141(1):255-268. doi:10. 1016/j.ijpe.2012.06.022

Huang X, Qiao L (2012) A risk index model for multi-period uncertain portfolio selection. Inf Sci 217:108-116. doi:10.1016/j. ins.2012.06.017

Huisman KJM, Kort PM (2004) Strategic technology adoption taking into account future technological improvements: a real options approach. Eur J Oper Res 159(3):705-728. doi:10.1016/S03772217(03)00421-1

Khallaf A (2012) Information technology investments and nonfinancial measures: a research framework. Account Forum 36(2):109-121. doi:10.1016/j.accfor.2011.07.001

Kim YJ, Sanders GL (2002) Strategic actions in information technology investment based on real option theory. Decis Support Syst 33(1):1-11. doi:10.1016/S0167-9236(01)00134-8

Koetter M, Noth F (2013) IT use, productivity, and market power in banking. J Financ Stab. doi:10.1016/j.jfs.2012.06.001

Kumar N (1996) The power of trust in manufacturer-retailer relationships. Harv Bus Rev 74(6):92

Lestage R, Flacher D, Kim Y, Kim J, Kim Y (2013) Competition and investment in telecommunications: Does competition have the same impact on investment by private and state-owned firms? Inf Econ Policy 25(1):41-50. doi:10.1016/j.infoecopol.2013.02.001

Levaggi R, Moretto M, Pertile P (2012) Static and dynamic efficiency of irreversible health care investments under alternative payment rules. J Health Econ 31(1):169-179. doi:10.1016/j.jhealeco. 2011.09.005

Li S, Blake A, Thomas R (2013) Modelling the economic impact of sports events: the case of the Beijing Olympics. Econ Model 30:235-244. doi:10.1016/j.econmod.2012.09.013

Luehrman TA (1998a) Investment opportunities as real options: getting started on the numbers. Harv Bus Rev 76:51-66

Luehrman TA (1998b) Strategy as a portfolio of real options. Harv Bus Rev 76:89-101
Martzoukos SH, Zacharias E (2013) Real option games with R\&D and learning spillovers. Omega 41(2):236-249. doi:10.1016/j. omega.2012.05.005

McIntyre DP, Chintakananda A (2013) A real options approach to releasing "network" products. J High Technol Manag Res 24(1):42-52. doi:10.1016/j.hitech.2013.02.007

Merali Y, Papadopoulos T, Nadkarni T (2012) Information systems strategy: Past, present, future? J Strateg Inf Syst 21(2):125-153. doi:10.1016/j.jsis.2012.04.002

Meyer E, Rees R (2012) Watchfully waiting: medical intervention as an optimal investment decision. J Health Econ 31(2):349-358. doi:10.1016/j.jhealeco.2012.02.002

Nadiminti R, Mukhopadhyay T, Kriebel CH (2002) Research report: intrafirm resource allocation with asymmetric information and negative externalities. Inf Syst Res 13(4):428-434. Retrieved from http://www.jstor.org/stable/23015723

Nishihara M (2011) A Real Options Game Involving Multiple Projects. In: Proceedings of the international multiconference of engineers and computer scientists

Pendharkar PC (2010) Valuing interdependent multi-stage IT investments: a real options approach. Eur J Oper Res 201(3):847-859

Podoynitsyna K, Song M, van der Bij H, Weggeman M (2013) Improving new technology venture performance under direct and indirect network externality conditions. J Bus Ventur 28(2):195-210. doi:10.1016/j.jbusvent.2012.04.004

Rohlfs W, Madlener R (2013) Investment decisions under uncertainty: CCS competing with green energy technologies. Energy Proc 37:7029-7038. doi:10.1016/j.egypro.2013.06.638

Schwienbacher A (2013) The entrepreneur's investor choice: the impact on later-stage firm development. J Bus Ventur 28(4):528-545. doi:10.1016/j.jbusvent.2012.09.002

Smit HT, Trigeorgis L (2006) Real options and games: competition, alliances and other applications of valuation and strategy. Rev Financ Econ 15(2):95-112

Smith JE, McCardle KF (1998) Valuing oil properties: integrating option pricing and decision analysis approaches. Oper Res 46(2):198-217

Smith JE, McCardle KF (1999) Options in the real world: lessons learned in evaluating oil and gas investments. Oper Res 47(1):1-15

Taudes A, Feurstein M, Mild A (2000) Options analysis of software platform decisions: a case study. MIS Q 24(2):227-243

van Zee RD, Spinler S (2014) Real option valuation of public sector R\&D investments with a down-and-out barrier option. Technovation. doi:10.1016/j.technovation.2013.06.005

Wang B, Wang X, Wang J (2012) Construction and empirical analysis of agricultural science and technology enterprises investment risk evaluation index system. IERI Proc 2:485-491. doi:10.1016/j.ieri.2012.06.121

Wrzaczek S, Kort PM (2012) Anticipation in innovative investment under oligopolistic competition. Automatica 48(11):2812-2823. doi:10.1016/j.automatica.2012.08.007

Wu L-C, Ong C-S (2008) Management of information technology investment: a framework based on a Real Options and MeanVariance theory perspective. Technovation 28(3):122-134. doi:10.1016/j.technovation.2007.05.011

Wu L-C, Li S-H, Ong C-S, Pan C (2012) Options in technology investment games: the real world TFT-LCD industry case. Technol Forecast Soc Change 79(7):1241-1253. doi:10.1016/j. techfore.2012.03.008 